https://doi.org/10.46344/JBINO.2021.v10i03.12

\title{
ADAPTABILITY PERFORMANCE OF FEED BARLEY GENOTYPES EVALUATED UNDER NWPZ OF THE COUNTRY
}

\author{
Ajay Verma, RPS Verma, J Singh, L Kumar and GP Singh
}

ICAR-Indian Institute of Wheat \& Barley Research, Karnal Haryana

\begin{abstract}
Highly significant effects of the environment (E), genotypes (G), and GxE interaction had been observed by AMMI analysis. Environment explained $63.4 \%$ whereas GxE interaction accounted for $23.4 \%$ of treatment variations in yield during first year. Harmonic Mean of Genotypic Values (HMGV) expressed higher values for PL906, KB1707, UPB1080 genotypes. Ranking of genotype as per IPCA-1 were NDB1723, NDB 1709, HUB266. While IPCA-2, selected BH1023, BH1024, NDB1723 genotypes. Values of Measures ASV1 selected NDB1723, NDB1709, HUB266 and ASV identified NDB1723, NDB 1709, BH1023 barley genotypes. Adaptability measures Harmonic Mean of Relative Performance of Genotypic Values (HMPRVG) pointed towards PL906, KB1707, UPB 1080 and Relative Performance of Genotypic Values (RPGV) identified KB1707, PL906, RD2994 as the genotypes of performance among the locations. Biplot graphical analysis observed clustering of adaptability measures PRVG, HMPRVG, along with GM, HM in a group. During 2019-20 cropping season Environment effects accounted $61.4 \%$ whereas GxE interaction contributed for $26.9 \%$ of treatment variations in yield. HMGV expressed higher values for DWRB137, PL906. IPCA-1 scores, desired ranking of genotypes was UPB1080, PL906. While IPCA-2 pointed towards PL906, RD2994, as genotypes of choice. Analytic measures ASV and ASV1 selected PL906, UPB 1080 barley genotypes. HMRPGV selected DWRB137, PL906 whereas PRVG settled for DWRB137, KB1707. Biplot analysis seen cluster of ASV, ASVI IPC 1, Mean, GM, HM along with adaptability measures PRVG, HMPRVG observed in adjacent quadrant.
\end{abstract}

Keywords : AMMI, ASV, ASV1, HMGV, GAI, HMPRVG, Biplots 


\section{Introduction}

Barley (Hordeum vulgare L.) is frequently being described as the most cosmopolitan of the crops as it is grown over the wide environmental range than any other cereal (Kharub et al 2017; Bocianowsk et al 2019). Also known, as "poor man's crop" due to low input requirements and better adaptability to harsh conditions (Kendel et al 2019). Traditionally the crop cultivated and used as a grain crop for human consumption as well feed for animals (Karkee et al 2020). Barley is particularly cultivated in the high-altitude areas of Himalaya as consumed by tribal people as food in the hilly areas (Kendel et al 2019). Grains consist of ample quantity of B-glucan beneficial in decreasing the glucose level of diabetic patients and to reduce the cholesterol of heart patients (Shimizu et al. 2008). GxE interaction analysis under multi location trials carried out by $A M M I$ analytic tools (Agahi et al 2020). Researchers gave more emphasis to identification of genotypes would express stable yield along with broad or narrow adaptation of the genotypes to environments (Bocianowsk et al 2019). Quite large number of measures for stability and adaptability of genotypes based on AMMI had observed in literature ( Tekdal \& Kendal 2018). Analytic measure of adaptability as the harmonic means of the relative performance of the predicted genotypic values (MHPRVG) utilized productivity, stability, and adaptability simultaneously of genotypes (Resende \& Durate 2007). Comparative performance of AMMI based measures had been studied with relatively new adaptability measures for feed barley genotypes evaluated under North Western Plains Zone of the country.

\section{Material and methods}

Parts of sub-humid Sutlej-Ganga Alluvial Plains and arid western plains, which comprises Punjab, Haryana, Delhi, Rajasthan (except Kota and Udaipur divisions), Western Uttar Pradesh (except Jhansi division and hilly areas), parts of Jammu and Kashmir (Jammu and Kathua districts) and parts of Himachal Pradesh (Paonta Valley and Una districts) categorized as the North Western Plain Zone of India. During cropping seasons of 2018-19 and 2019-20 twenty one genotypes in advanced trials evaluated at six major locations of the zone and eight genotypes at eight locations respectively. Field trials were conducted at research centers in randomized complete block designs with three replications. Recommended agronomic practices were followed to harvest good yield. Details of locations and genotype parentage were reflected in tables 1 \& 2 for ready reference.
$\begin{array}{ll}\text { Mohamadi \& Amri } 2008 & \begin{array}{l}\text { Geometric Mean as Adaptability } \\ \text { Index }\end{array}\end{array}$
Purchase1997
AMMI stability value
$\mathrm{GAI}=\sqrt[n]{\prod_{\mathrm{k}=1}^{\mathrm{n}} \overline{\mathrm{X}}_{\mathrm{k}}}$
$\left.\mathrm{ASV}=\left[\mathrm{SSIPC1}_{\operatorname{SSIPC2} 2} P C I\right)^{2}+(P C 2)^{2}\right]^{1 / 2}$
Zali et al2012
AMMI stability value
$\mathrm{ASV} 1=\left[\frac{\operatorname{SSIPC1} 1}{\operatorname{SIPC} 2}(P C I)^{2}+(P C 2)^{2}\right]^{1 / 2}$

Resende 2004

Harmonic mean of Genetic $\mathrm{MHVG}_{\mathrm{i}}=$ Number of environments $/ \sum_{i=1}^{k} \frac{1}{x_{i}}$

2021 May Edition | www.jbino.com | Innovative Association 


$\begin{array}{lll}\text { Resende \& Durate 2007 } & \begin{array}{l}\text { Values } \\ \text { Relative performance of genotypic } P R V G_{i j}=V_{i j} / V_{i} \\ \text { values across environments }\end{array} \\ \text { Resende \& Durate 2007 } & \begin{array}{l}\text { Harmonic mean of Relative } \\ \text { performance of genotypic values }\end{array} \quad M_{P R V G}=\text { Number of environments } / \sum_{j=1}^{k} \frac{1}{P^{k} V G_{i j}}\end{array}$

AMMI analysis was performed using AMMISOFT version 1.0, available at https://scs.cals.cornell.edu/people/ hugh-gauch/and SAS software version 9.3. Simple and effective measure for adaptability is calculated as the relative performance of genetic values (PRVG) across environments and MHVG (Harmonic mean of Genetic Values), based on the harmonic mean of the genotypic values across in different environments. Lower the standard deviation of genotypic performance across environments, the greater is the harmonic mean of its genotypic values.

\section{Results and discussion}

\section{AMMI analysis of barley genotypes First year of study 2018-19}

Adaptability performance of barley genotypes studied by AMMI based measures. These measures evaluate the performance after reduction of the noise from the GxE interaction effects (Gauch 2013). Highly significant effects of the environment (E), genotypes (G), and GXE interaction had been observed by AMMI analysis (Table 3). Analysis observed the greater contribution of environments, GXE interactions, and genotypes to the total sum of squares (SS) as compared to the residual effects. Environment explained about significantly $63.4 \%$ of the total sum of squares due to treatments indicating that diverse environments caused most of the variations in genotypes yield. Genotypes explained only $9.1 \%$ of a total sum of squares, whereas GXE interaction accounted to the tune of $23.4 \%$ of treatment variations in yield. Further bifurcation of GXE interaction observed the significant four multiplicative terms most of the interaction sum of squares as compared to residual / noise (Oyekunle et al 2017).

\section{Second year 2019-20}

Analysis observed the greater contribution of environments, GXE interactions, and genotypes to the total sum of squares (SS) as compared to the residual effects. Environment explained about significantly $61.4 \%$, GxE interaction accounted for $26.9 \%$ whereas Genotypes explained only $3.6 \% \%$ of the total sum of squares due to treatments. Partitioning of GXE interaction two highly significant multiplicative terms out of six explained more of the interaction sum of squares.

\section{Ranking of genotypes as per descriptive measures}

\section{First year of study 2018-19}

An average yield of genotypes over the studied locations selected KB1707, PL906, RD2994 as higher productive genotypes (Table 4). Though this measure is simple to calculate, but failed to exploit full information contained in dataset as per the field performance. Geometric mean is used to evaluate the adaptability of genotypes. Geometric mean observed PL906, KB1707, UPB 1080 were top-ranked genotypes. Harmonic Mean of Genotypic Values of yield expressed higher values for PL906, KB1707, UPB1080 genotypes. Consistent yield performance of genotypes judged by lower values of Coefficient of Variation and genotypes $\mathrm{KB} 1713$, DWRB205, BH1023 would be suitable for considered locations of this zone of the country. Minimum values of standard deviation of yield values 
selected KB1713, DWRB205, HUB266 barley genotypes.

\section{Second year 2019-20}

Average yield selected DWRB137, PL906 genotypes for higher values (Table 8). Geometric mean observed DWRB137, PL906 were with top-rank. Harmonic mean of genetic values (HMGV) expressed higher values for DWRB137, PL906 genotypes.

Consistent yield performance of UPB 1080, DWRB137 judged by lower values of Coefficient of Variation. Minimum values of standard deviation of yield values selected UPB1080, DWRB137 barley genotypes. Analytic measures PRVG, MHVG, and MHPRVG, had showed consensus for classification of genotypes as per raking of genotypes vis-à-vis analytic measures (Table 6). Presence of significant cross over interactions has been validated by differences among ranks of genotypes vis-à-vis locations of the zone.

\section{Adaptability behaviour of genotypes First year of study 2018-19}

The IPCA scores of a genotype in AMMI analysis indicate the stability or adaptation over environments. The greater the IPCA scores, either negative or positive (as it is a relative value), the more specifically adapted is the genotype to certain environments. The more the IPCA scores approximate zero, the more stable or adapted the genotypes. Adaptability of genotypes over locations indicated by the IPCA scores in the AMMI analysis. Ranking of genotype as per absolute IPCA-1 scores were NDB1723, NDB1709, HUB266 (Table 5). While for IPCA-2, genotypes BH1023, BH1024, NDB1723 would be of choice. Values of IPCA-3 favored NDB1709,
KB1707, RD2552 barley genotypes. Lower Values of IPCA-4 settled for UPB1080, KB1707, RD2991 barley genotypes.

Analytic measures of adaptability ASV and ASVIconsider two significant IPCAs of the AMMI analysis for adaptability behaviour (Tekdal \& Kendal 2018). Values of ASV1 selected NDB1723, NDB1709, HUB266 and ASV identified NDB1723, NDB1709, BH1023 barley genotypes. Harmonic Mean of Relative Performance of Genotypic Values (HMRPGV) method, the genotypes can be simultaneously sorted by genotypic values (yield) and stability using the harmonic means of the yield so that the smaller the standard deviation of genotypic performance among the locations. Values of HMRPGV ranked PL906, KB1707, UPB1080 as the performance of the genotypes among the locations. When considering the yield and adaptability simultaneously, the recommended approach is the relative performance of genetic values (RPGV) overcrop years. Relative Performance of Genotypic Values had settled for KB1707, PL906, RD2994 genotypes. Analytic measures PRVG, MHVG, and MHPRVG, had showed consensus for classification of genotypes as per raking of genotypes vis-à-vis analytic measures. Presence of significant cross over interactions has been validated by differences among ranks of genotypes vis-à-vis locations of the zone.

\section{Second year 2019-20}

UPB 1080, PL906 were the top ranked genotype as per absolute IPCA-1 scores (Table 8). While for IPCA-2 identified PL906, RD2994 genotypes would be of choice. Values of IPCA-3 favoured KB1707, PL906 barley genotypes. As per IPCA-4, KB1707, DWRB137 genotypes would be of stable performance. 
Minimum values of IPCA-5 settled for KB1707, RD2552 barley genotypes. Genotypes DWRB137, PL906 identified by as per IPCA-6 measure. Two significant IPCAs of the AMMI analysis considered by ASV and ASV 1 for adaptability behaviour of genotypes. Both measures selected same set of PL906, UPB1080 barley genotypes. Harmonic Mean of Relative Performance of Genotypic Values (HMRPGV) values ranked DWRB137, PL906 as of stable performance among the locations. Relative Performance of Genotypic Values (RPGV) had settled for DWRB137, KB1707 genotypes.

\section{Biplot analysis}

\section{First year of study 2018-19}

Graphical analysis to understand the association if any among adaptability measures utilized the first two highly significant Interaction Principal Components of analysis. First two significant interaction principal components contribute to the tune of $39.6 \%$ \& $21.8 \%$ to the total for $61.5 \%$ of total GxE interaction sum of squares (Figure 1). Loadings of adaptability measures based on significant two interaction principal components had mentioned in table 6. Biplot observed cluster of CVs with IPC3 whereas Sdev grouped with mean, IPC I IPC2. Cluster of ASV and ASV1 observed with IPC4 measures in one quadrant and adaptability measures PRVG, HMPRVG, along with GM, HM grouped in a separate cluster.

\section{Second year 2019-20}

First two significant interaction principal components accounted total for $52.8 \%$ with respective share of $32.5 \%$ \& $20.3 \%$ of total GxE interaction sum of squares
(Figure 2). Loadings of adaptability measures based on two interaction principal components had mentioned in table 10. Measure CV clustered with Sdev, IPC4 in one quadrant of biplot analysis. ASV, ASVI IPC1, Mean, GM, HM along with adaptability measures PRVG, HMPRVG observed in adjacent quadrant. IPC2 and IPC5 joined hands in one quadrant while IPC3 \& IPC6 were grouped together in next quadrant.

\section{Conclusions}

Researchers concentrates on genotypes with high productive potential that respond to favorable environments. Often the occurrence of complex type GxE interaction leads to uncertainty in the identification of promising genotype; in this case, techniques exploit adaptability and stability can provide precise information about genotypes performance. The identification of stable and highly productive genotypes between different environments remains a constant challenge for breeders of various crop species around the world. Selection of barley genotypes by the harmonic mean of genotypic values allow to identify the stable and productive genotypes.

\section{Acknowledgements}

Barley genotypes were evaluated at coordinated centers of AICW\&BIP across the country. Authors sincerely acknowledge the hard work of all the staff for field evaluation and data recording.

\section{Conflict of interest}

No conflict of interest 
Agahi K., Jafar Ahmadi, Hassan Amiri Oghan, Mohammad Hossein Fotokian and Sedigheh Fabriki Orang (2020) Analysis of genotype $x$ environment interaction for seed yield in spring oilseed rape using the $\mathrm{AMMI}$ model. Crop Breeding and Applied Biotechnology 20(1): e26502012

Bocianowsk J, Warzecha T, Nowosad K, \& Bathelt R (2019) Genotype by environment interaction using $A M M I$ model and estimation of additive and epistasis gene effects for 1000-kernel weight in spring barley (Hordeum vulgare L.). Journal of Applied Genetics, 60: 127135.

Gauch HG (2013) A Simple Protocol for AMMI Analysis of Yield Trials. Crop Science 53:1860-1869.

Karkee A, Ghimire K H and Joshi, B K. 2020. Evaluation on naked barley landraces for agro-morphological traits. Journal of Nepal Agricultural Research Council. 6:34-43.

Kendel M, Dhami N B and Shrestha J. 2019. Performance evaluation of barley (Hordeum vulgare L.) genotypes in Dolakha, Nepal: from yielding perspective. Journal of Agriculture and Natural Resources 2(1):322-337.

Kharub Ajit Singh, Kumar D., Kumar Vishnu, Malik Rekha, Verma Ramesh Pal Singh, Sharma Indu. (2017). Barley research in India: challenges and opportunities. Haryana, India: Indian Council of Agricultural Research, Indian Institute of Wheat and Barley Research (ICAR-IIWBR).
Kendal E, Tekdal S(2016) Application of AMMI Model for Evolution Spring Barley Genotypes in Multi-Environment Trials. Bangladesh J. Bot. 45(3): 613-620.

Mohammadi $R$ and Amri $A(2008)$ Comparison of parametric and nonparametric methods for selecting stable and adapted durum wheat genotypes in variable environments. Euphytica 159: 419-432.

Oyekunle, M., A. Menkir, H. Mani, G. Olaoye, I.S. Usman, S.G. Ado et al. 2017. Stability analysis of maize cultivars adapted to tropical environments using AMMI analysis. Cereal Res. Commun. 45:336-345.

Purchase JL (1997) Parametric analysis to describe $G \times E$ interaction and yield stability in winter wheat. Ph.D. thesis. Dep. of Agronomy, Faculty of Agriculture, Univ. of the Orange Free State, Bloemfontein, South Africa.

Rao AR, Prabhakaran VT(2005) Use of $A M M I$ in simultaneous selection of genotypes for yield and stability. Journal of the Indian Society of Agricultural Statistics 59:76-82.

Resende MDV de and Duarte JB. 2007. Precision and quality control in variety trials. Pesquisa Agropecuaria Tropical. 37(3): 182-194.

Shimizu C, Kihara M, Aoe S, Araki A, Ito K, Hayashi K, Watari J, Sakata $Y$ and Ikegami S. 2008. Effect of high B-glucan barley on serum cholesterol concentrations and visceral fat area in Japanese men- A randomized, double- 
blinded, placebo-controlled trial. Plant Food Human Nutrition 63:21-25

Tekdal S, Kendal E (2018) AMMI Model to Assess Durum Wheat Genotypes in MultiEnvironment Trials. J Agr Sci Tech . 20: 153-166

Zali H, Farshadfar E, Sabaghpour SH, Karimizadeh $R$ (2012) Evaluation of genotype $\times$ environment interaction in chickpea using measures of stability from AMMI model. Annals of Biological Research 3(7):

3126-3136. 


\section{J.Bio.Innov10(3), pp: 00-00, 2021 | ISSN 2277-8330 (Electronic)}

Table 1: Parentage details of barley genotypes and environmental conditions (2018-19)

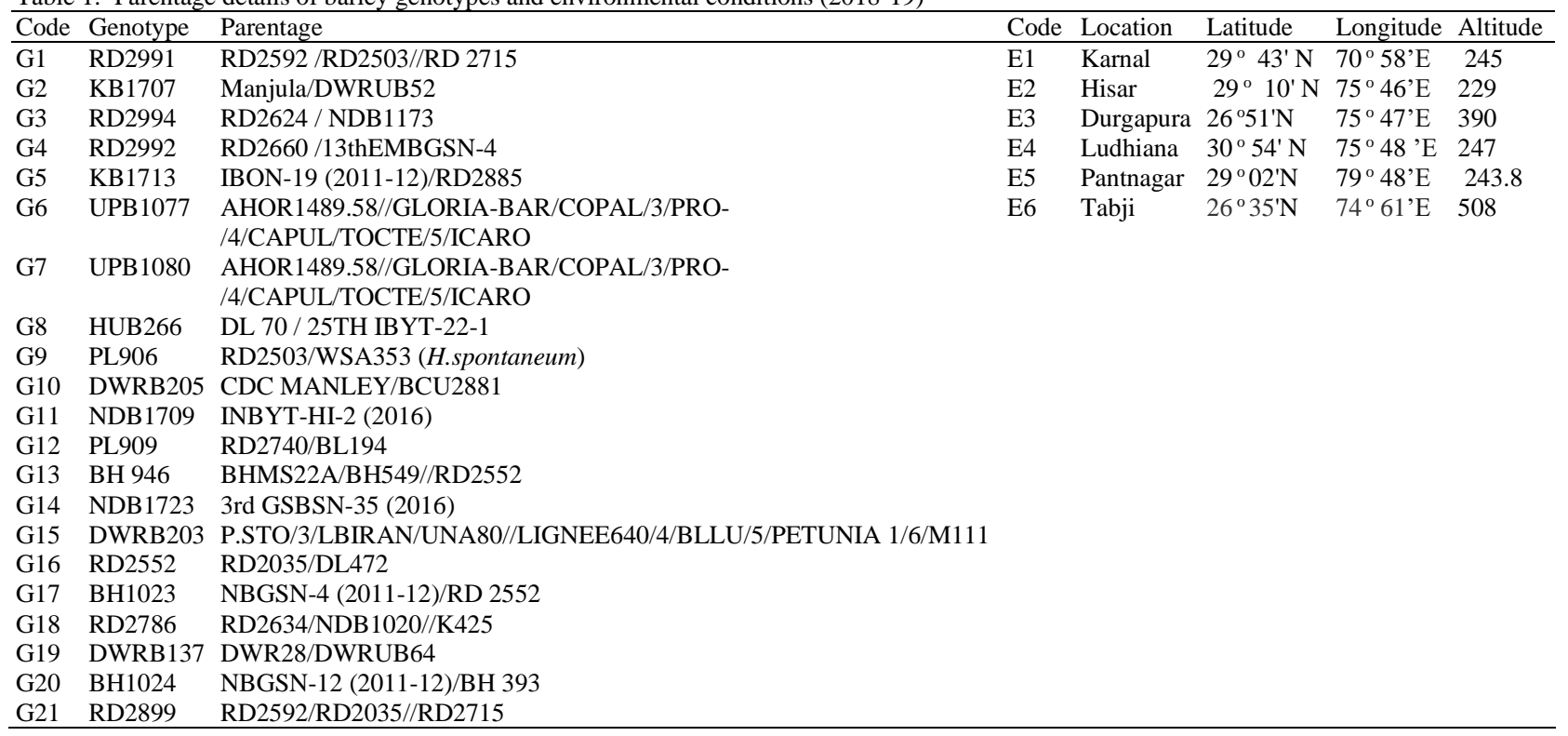

Table 2: Parentage details of barley genotypes and environmental conditions (2019-20)

\begin{tabular}{|c|c|c|c|c|c|c|c|}
\hline Code & Genotype & Parentage & Code & Location & Latitude & Longitude & Altitude \\
\hline G1 & BH946 & BHMS22A/BH549//RD2552 & E1 & Durgapura & $26^{\circ} 51^{\prime} \mathrm{N}$ & $75^{\circ} 47^{\prime} \mathrm{E}$ & 390 \\
\hline G2 & RD2994 & RD2624 / NDB1173 & E2 & Hisar & $29^{\circ} 10^{\prime} \mathrm{N}$ & $75^{\circ} 46^{\prime} \mathrm{E}$ & 229 \\
\hline G3 & DWRB137 & DWR28/DWRUB64 & E3 & Karnal & $29^{\circ} 43^{\prime} \mathrm{N}$ & $70^{\circ} 58^{\prime} \mathrm{E}$ & 245 \\
\hline G4 & PL906 & RD2503/WSA353 (H.spontaneum) & E4 & Ludhiana & $30^{\circ} 54^{\prime} \mathrm{N}$ & $75^{\circ} 48^{\prime} \mathrm{E}$ & 247 \\
\hline G5 & BH902 & BH495/RD2552 & E5 & Modipuram & $29^{\circ} 05^{\prime} \mathrm{N}$ & $77^{\circ} 70^{\prime} \mathrm{E}$ & 226 \\
\hline G6 & RD2552 & RD2035/DL472 & E6 & Pantnagar & $29^{\circ} 02^{\prime} \mathrm{N}$ & $79^{\circ} 48^{\prime} \mathrm{E}$ & 243.8 \\
\hline G7 & UPB 1080 & $\begin{array}{l}\text { AHOR1489.58//GLORIA-BAR/COPAL/3/PRO- } \\
\text { /4/CAPUL/TOCTE/5/ICARO }\end{array}$ & E7 & Tabiji & $26^{\circ} 35^{\prime} \mathrm{N}$ & $74^{\circ} 61^{\prime} \mathrm{E}$ & 508 \\
\hline G8 & KB1707 & Manjula/DWRUB52 & E8 & Udaipur & $24^{\circ} 34^{\prime} \mathrm{N}$ & $73^{\circ} 41^{\prime} \mathrm{E}$ & 585 \\
\hline
\end{tabular}


Table 3: Multi environment trails analysis by AMMI of barley genotypes (2018-19)

\begin{tabular}{|c|c|c|c|c|}
\hline Source & Degree of freedom & Mean Sum of Squares & Significance level & $\%$ contributions of factors \\
\hline Treatments & 125 & 638.79 & $.0000000 * * *$ & 95.94 \\
\hline Genotypes (G) & 20 & 378.02 & $.0000000 * * *$ & 9.08 \\
\hline Environments (E) & 5 & 10555.55 & $.0000000 * * *$ & 63.42 \\
\hline Interactions $(\mathrm{GxE})$ & 100 & 195.11 & $.0000000 * * *$ & 23.44 \\
\hline IPC1 & 24 & 305.44 & $.0000000 * * *$ & \\
\hline IPC2 & 22 & 228.62 & $.0000000 * * *$ & \\
\hline IPC 3 & 20 & 186.59 & $.0000000 * * *$ & \\
\hline IPC4 & 18 & 116.28 & $.0000000 * * *$ & \\
\hline Residual & 16 & 82.85 & $.0000000 * * *$ & \\
\hline Error & 252 & 13.40 & & \\
\hline Total & 377 & 220.75 & & \\
\hline
\end{tabular}

Table 4: Ranking of barley genotypes as per descriptive measures (2018-19)

\begin{tabular}{|c|c|c|c|c|c|c|c|c|c|c|c|c|c|c|c|c|}
\hline Genotype & Karnal & Hisar & Durgapura & Ludhiana & Pantnagar & Tabji & MEAN & $\mathrm{R}_{\mathrm{k}}$ & GM & $\mathrm{R}_{\mathrm{k}}$ & $\mathrm{HM}$ & $\mathrm{R}_{\mathrm{k}}$ & $\mathrm{CV}$ & $\mathrm{R}_{\mathrm{k}}$ & Sdev & $\mathrm{R}_{\mathrm{k}}$ \\
\hline RD2991 & 40.74 & 39.45 & 71.01 & 19.86 & 36.78 & 39.45 & 41.22 & 20 & 38.56 & 20 & 35.96 & 20 & 0.4016 & 20 & 16.55 & 14 \\
\hline KB1707 & 89.78 & 47.99 & 76.81 & 51.26 & 39.81 & 34.22 & 56.65 & 1 & 53.37 & 2 & 50.49 & 2 & 0.3863 & 19 & 21.88 & 21 \\
\hline RD2994 & 78.75 & 34.38 & 66.43 & 52.34 & 39.85 & 52.74 & 54.08 & 3 & 52.01 & 4 & 50.00 & 4 & 0.3045 & 11 & 16.47 & 13 \\
\hline RD2992 & 62.24 & 30.28 & 53.86 & 17.17 & 29.55 & 39.45 & 38.76 & 21 & 35.59 & 21 & 32.42 & 21 & 0.4321 & 21 & 16.75 & 16 \\
\hline KB1713 & 44.77 & 43.72 & 62.56 & 44.69 & 41.97 & 44.28 & 47.00 & 14 & 46.55 & 12 & 46.16 & 10 & 0.1637 & 1 & 7.69 & 1 \\
\hline UPB1077 & 53.62 & 39.05 & 70.29 & 29.79 & 48.49 & 38.24 & 46.58 & 17 & 44.84 & 17 & 43.22 & 16 & 0.3071 & 14 & 14.31 & 10 \\
\hline UPB1080 & 79.79 & 43.08 & 66.18 & 41.87 & 37.12 & 56.36 & 54.07 & 4 & 52.07 & 3 & 50.24 & 3 & 0.3062 & 13 & 16.56 & 15 \\
\hline HUB266 & 56.52 & 41.14 & 67.39 & 45.89 & 39.29 & 36.63 & 47.81 & 12 & 46.69 & 11 & 45.67 & 12 & 0.2483 & 4 & 11.87 & 3 \\
\hline DWRB205 & 49.60 & 39.85 & 55.79 & 40.26 & 33.11 & 61.59 & 46.70 & 16 & 45.65 & 14 & 44.63 & 14 & 0.2318 & 2 & 10.83 & 2 \\
\hline NDB1709 & 61.35 & 33.57 & 64.73 & 37.57 & 39.60 & 44.69 & 46.92 & 15 & 45.49 & 16 & 44.19 & 15 & 0.2778 & 7 & 13.04 & 7 \\
\hline PL909 & 74.40 & 44.12 & 64.73 & 39.18 & 34.23 & 52.74 & 51.57 & 7 & 49.68 & 7 & 47.90 & 7 & 0.3011 & 10 & 15.53 & 12 \\
\hline BH 946 & 69.56 & 51.45 & 71.02 & 25.76 & 37.29 & 37.04 & 48.69 & 11 & 45.64 & 15 & 42.70 & 17 & 0.3824 & 18 & 18.62 & 20 \\
\hline NDB 1723 & 57.89 & 39.13 & 60.63 & 36.23 & 29.95 & 42.27 & 44.35 & 19 & 42.98 & 19 & 41.68 & 18 & 0.2767 & 6 & 12.27 & 5 \\
\hline DWRB203 & 65.14 & 38.41 & 67.15 & 48.04 & 44.07 & 32.21 & 49.17 & 10 & 47.48 & 10 & 45.86 & 11 & 0.2889 & 9 & 14.21 & 9 \\
\hline RD2552 & 58.70 & 43.24 & 70.53 & 38.49 & 32.21 & 55.96 & 49.85 & 8 & 48.12 & 9 & 46.42 & 9 & 0.2875 & 8 & 14.33 & 11 \\
\hline BH1023 & 60.47 & 41.55 & 66.67 & 33.55 & 48.09 & 47.50 & 49.64 & 9 & 48.39 & 8 & 47.15 & 8 & 0.2449 & 3 & 12.15 & 4 \\
\hline RD2786 & 76.73 & 52.98 & 67.87 & 47.23 & 32.98 & 37.04 & 52.47 & 6 & 50.16 & 6 & 47.95 & 6 & 0.3269 & 17 & 17.16 & 18 \\
\hline BH1024 & 52.50 & 44.20 & 66.91 & 29.52 & 32.22 & 43.88 & 44.87 & 18 & 43.18 & 18 & 41.58 & 19 & 0.3057 & 12 & 13.72 & 8 \\
\hline RD2899 & 50.81 & 52.01 & 66.91 & 50.46 & 32.46 & 33.82 & 47.74 & 13 & 46.25 & 13 & 44.76 & 13 & 0.2698 & 5 & 12.88 & 6 \\
\hline
\end{tabular}

Table 5: Adaptability measures of barley genotypes evaluated under MET (2018-19)

\begin{tabular}{|c|c|c|c|c|c|c|c|c|c|c|c|c|}
\hline Genotype & IPC1 & IPC2 & IPC3 & IPC4 & ASV1 & $\mathrm{R}_{\mathrm{ASV} 1}$ & ASV & $\mathrm{R}_{\mathrm{ASV}}$ & PRVG & $\mathrm{R}_{\mathrm{PRVG}}$ & HMPRVG & $\mathrm{R}_{\text {HMPRVG }}$ \\
\hline RD2991 & -2.715 & -1.048 & 1.823 & -0.336 & 4.09 & 20 & 3.44 & 19 & 0.8366 & 20 & 0.7815 & 20 \\
\hline KB1707 & 3.630 & -1.478 & 0.196 & 0.189 & 5.49 & 21 & 4.62 & 21 & 1.1423 & 1 & 1.0990 & 2 \\
\hline
\end{tabular}

2021 May Edition |www.jbino.com | Innovative Association 


\begin{tabular}{|c|c|c|c|c|c|c|c|c|c|c|c|c|}
\hline Genotype & IPC1 & IPC2 & IPC3 & IPC4 & ASV1 & $\mathrm{R}_{\mathrm{ASV} 1}$ & ASV & $\mathrm{R}_{\mathrm{ASV}}$ & PRVG & $\mathrm{R}_{\mathrm{PRVG}}$ & HMPRVG & $\mathrm{R}_{\text {HMPRVG }}$ \\
\hline RD2994 & 1.721 & 1.634 & -1.214 & 1.752 & 2.99 & 16 & 2.64 & 16 & 1.1069 & 3 & 1.0784 & 4 \\
\hline RD2992 & 0.549 & 1.261 & 2.211 & 0.363 & 1.49 & 5 & 1.42 & 4 & 0.7707 & 21 & 0.7208 & 21 \\
\hline KB1713 & -2.133 & -0.959 & -1.670 & 0.392 & 3.25 & 17 & 2.75 & 17 & 0.9901 & 12 & 0.9652 & 12 \\
\hline UPB1077 & -1.399 & -1.434 & 1.485 & 1.691 & 2.49 & 13 & 2.22 & 13 & 0.9577 & 17 & 0.9287 & 17 \\
\hline UPB1080 & 1.359 & 1.965 & 0.433 & -0.087 & 2.79 & 15 & 2.56 & 15 & 1.1003 & 4 & 1.0885 & 3 \\
\hline HUB266 & -0.204 & -1.450 & -1.220 & 0.627 & 1.48 & 3 & 1.47 & 7 & 0.9876 & 13 & 0.9747 & 11 \\
\hline PL906 & 1.063 & 1.193 & -0.613 & -0.861 & 1.96 & 9 & 1.75 & 9 & 1.1325 & 2 & 1.1160 & 1 \\
\hline DWRB205 & -2.100 & 2.366 & -1.506 & -0.534 & 3.87 & 19 & 3.47 & 20 & 0.9764 & 15 & 0.9447 & 15 \\
\hline NDB1709 & -0.111 & 0.427 & 0.016 & 1.466 & 0.46 & 2 & 0.45 & 2 & 0.9597 & 16 & 0.9524 & 14 \\
\hline PL909 & 1.011 & 1.498 & 0.406 & -0.656 & 2.10 & 11 & 1.93 & 11 & 1.0487 & 7 & 1.0394 & 7 \\
\hline ВН 946 & 0.685 & -1.187 & 2.692 & -1.399 & 1.55 & 6 & 1.45 & 5 & 0.9790 & 14 & 0.9379 & 16 \\
\hline NDB1723 & -0.021 & 0.299 & -0.415 & -0.562 & 0.30 & 1 & 0.30 & 1 & 0.9044 & 19 & 0.9020 & 18 \\
\hline DWRB203 & 0.964 & -1.801 & -0.942 & 1.873 & 2.28 & 12 & 2.14 & 12 & 1.0130 & 10 & 0.9816 & 10 \\
\hline RD2552 & -1.037 & 1.298 & -0.199 & -1.137 & 1.99 & 10 & 1.80 & 10 & 1.0179 & 9 & 1.0051 & 9 \\
\hline BH1023 & -1.021 & -0.091 & 1.159 & 1.337 & 1.49 & 4 & 1.24 & 3 & 1.0253 & 8 & 1.0091 & 8 \\
\hline RD2786 & 2.209 & -1.139 & -0.403 & -1.588 & 3.41 & 18 & 2.90 & 18 & 1.0682 & 6 & 1.0398 & 6 \\
\hline DWRB137 & -0.732 & 1.227 & -0.681 & 0.430 & 1.63 & 7 & 1.51 & 8 & 1.0765 & 5 & 1.0585 & 5 \\
\hline BH1024 & -1.204 & -0.185 & 0.728 & -1.274 & 1.76 & 8 & 1.47 & 6 & 0.9135 & 18 & 0.9013 & 19 \\
\hline
\end{tabular}




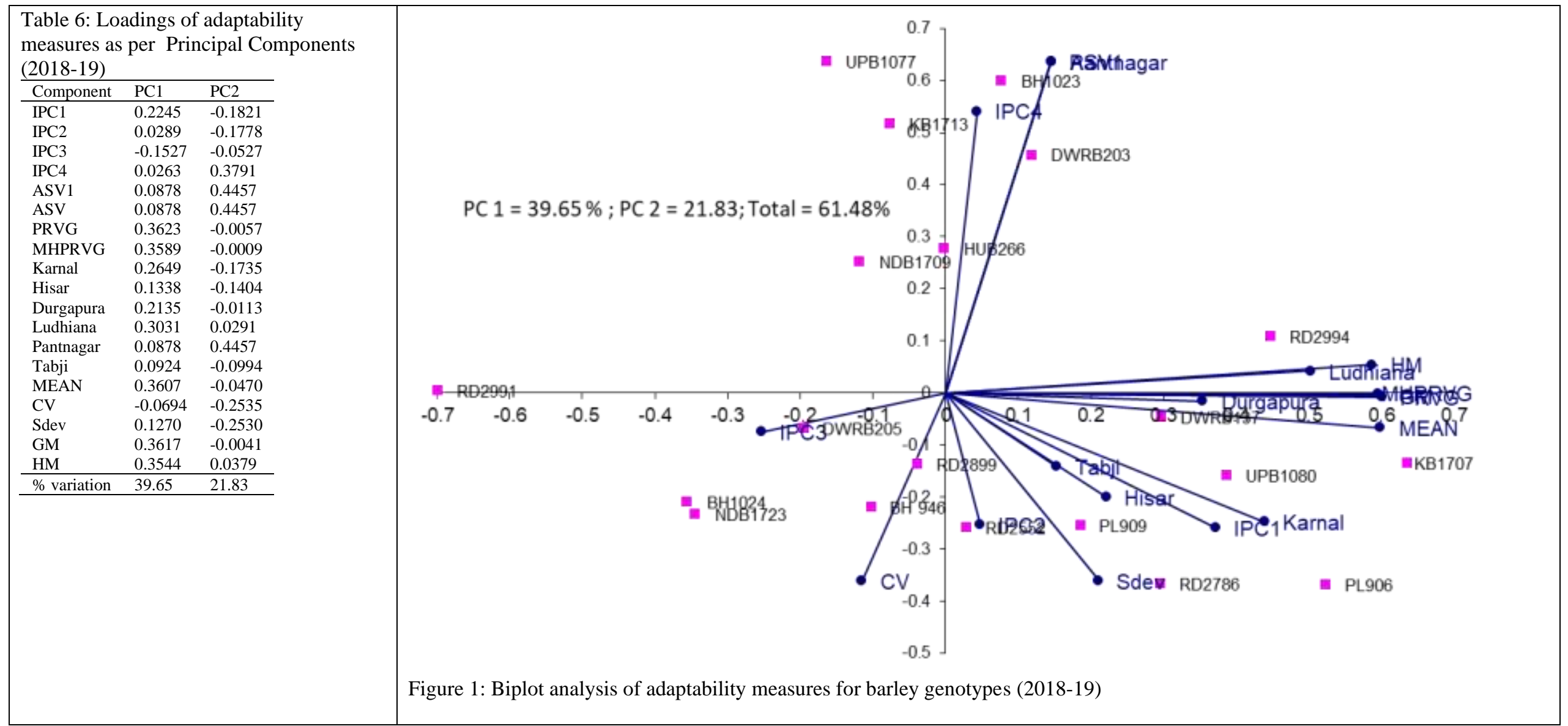


Table 7: Multi environment trails analysis by AMMI of barley genotypes (2019-20)

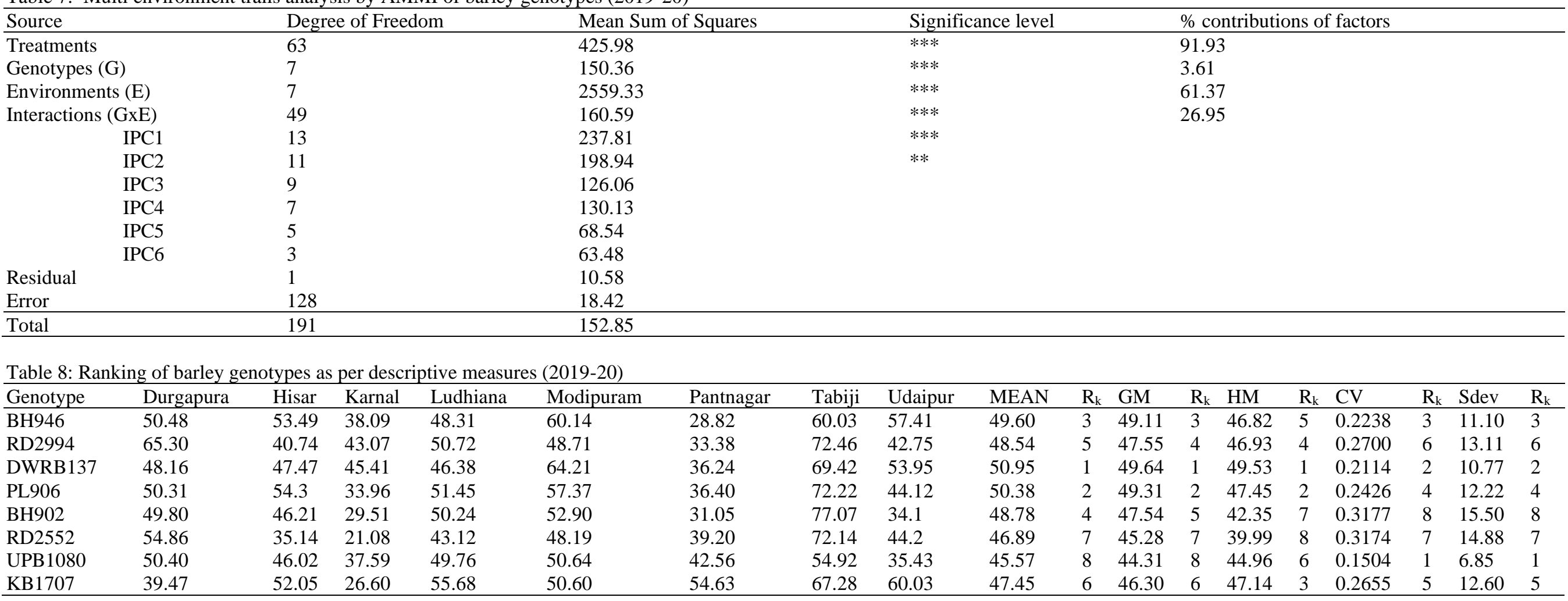

Table 9 : Adaptability measures of barley genotypes evaluated under MET (2019-20)

\begin{tabular}{|c|c|c|c|c|c|c|c|c|c|c|c|c|c|c|}
\hline Genotype & IPC1 & IPC2 & IPC3 & IPC4 & IPC5 & IPC6 & ASV1 & $\mathrm{R}_{\mathrm{ASV} 1}$ & ASV & $\mathrm{R}_{\mathrm{ASV}}$ & PRVG & $\mathrm{R}_{\mathrm{PRVG}}$ & HMPRVG & $\mathrm{R}_{\text {HMPRVG }}$ \\
\hline BH946 & 0.829 & 3.135 & -0.977 & 0.639 & -1.867 & 0.452 & 3.35 & 6 & 3.29 & 6 & 1.025 & 3 & 1.0034 & 4 \\
\hline RD2994 & -3.041 & -0.291 & 0.781 & 1.734 & -0.516 & -1.639 & 4.31 & 7 & 3.63 & 7 & 1.024 & 5 & 1.0025 & 5 \\
\hline DWRB137 & 0.194 & 2.298 & -0.954 & 0.507 & 2.561 & -0.121 & 2.31 & 3 & 2.31 & 3 & 1.067 & 1 & 1.0522 & 1 \\
\hline PL906 & -0.111 & 0.109 & -0.550 & -1.921 & -0.538 & 0.251 & 0.19 & 1 & 0.17 & 1 & 1.025 & 4 & 1.0212 & 2 \\
\hline BH902 & -1.673 & -1.236 & -1.096 & -2.524 & 0.098 & -0.363 & 2.67 & 4 & 2.34 & 4 & 0.937 & 7 & 0.9216 & 7 \\
\hline RD2552 & -0.515 & -2.700 & -1.185 & 1.831 & 0.088 & 1.625 & 2.80 & 5 & 2.77 & 5 & 0.905 & 8 & 0.8762 & 8 \\
\hline UPB1080 & -0.047 & 0.371 & 3.743 & -0.524 & 0.256 & 0.948 & 0.38 & 2 & 0.37 & 2 & 0.962 & 6 & 0.9464 & 6 \\
\hline KB1707 & 4.365 & -1.686 & 0.238 & 0.258 & -0.082 & -1.153 & 6.39 & 6 & 5.45 & 6 & 1.055 & 2 & 1.0092 & 3 \\
\hline
\end{tabular}




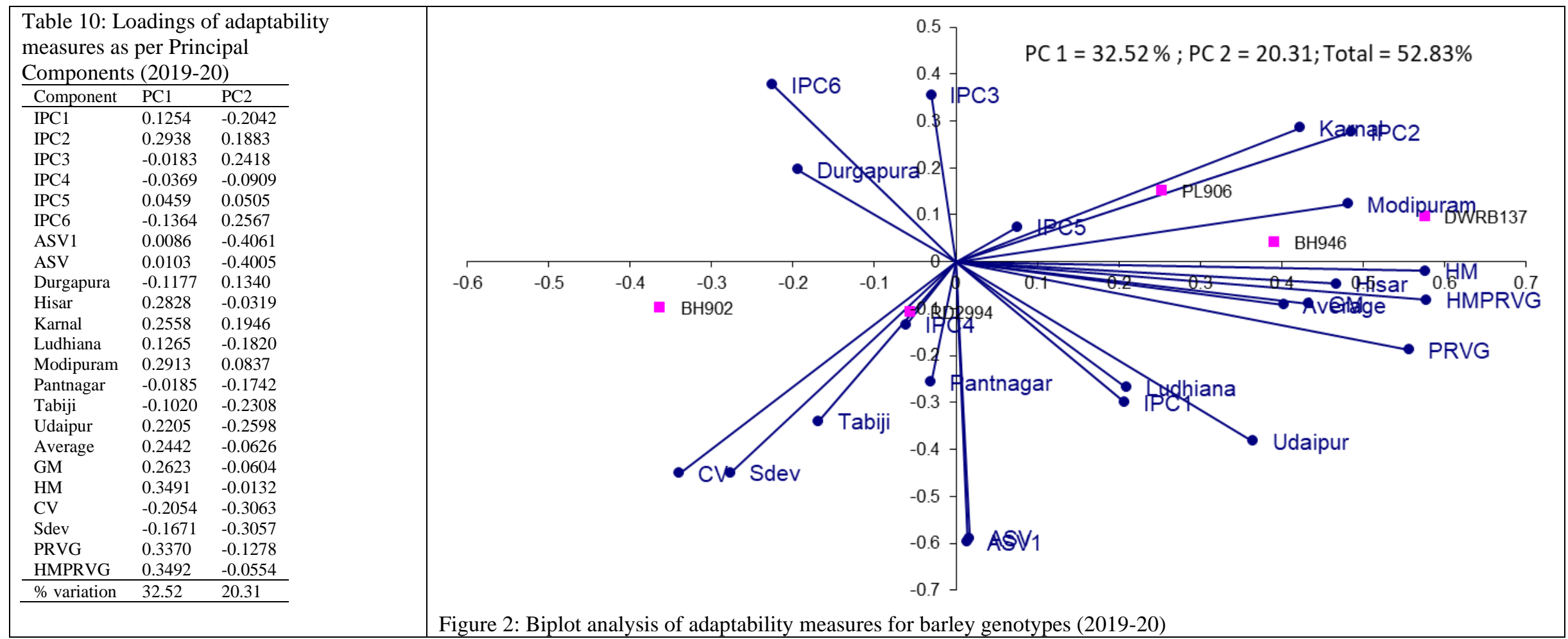

